\title{
Analysis of Transactions 212 Mart Kuto Palembang to Find Frequent Patterns Among Itemset Using Association Rule Mining
}

\author{
Zikri NURZANI ${ }^{1}$, and Ken Ditha TANIA ${ }^{2 *}$
}

\author{
${ }^{1}$ zikzani@gmail.com, ${ }^{2}$ kenya.tania@gmail.com, Information System Department, Faculty of Computer \\ Science,Sriwijaya University 30662 Palembang, Indonesia \\ *Corresponding author : kenya.tania@gmail.com
}

\begin{abstract}
Minimarket 212 Mart Palembang Kuto is a retail market of 212 mart cooperative cooperatives, selling various kinds of goods for daily needs ranging from food, non-food, drinks and frozen food. All transactions carried out in transactions, which are stored in datacenter warmart 212, consist of spreadsheets that start operating from February $21^{\text {th }}, 2019$. Transaction data that is recorded and stored in warehouses are large and piling up, it is estimated that there are 58,068 transactions until February $21^{\text {th }}, 2019$. Therefore, Data mining is used to create transaction data that is needed by getting information in the data using the rule association method with depth-first search or eclat search algorithm. Results obtained from the owners of 212 Palembang Kuto with the hope of increasing sales through bundling of goods, the right promotion and refilling of goods accordingly.
\end{abstract}

Keywords: data mining, association rules, transaction, eclat

\section{Introduction}

Retail markets are currently facing dynamics and competitiveness in looking for better market campaigns. The development of minimarkets is caused by several factors. The factor of increasing the population in Indonesia can increase the number of potential customers for minimarkets. An increase in per capita income which has an impact on increasing people's purchasing power. Other factors that influence are people's behavior in shopping in urban communities who want comfort, cleanliness, variety of products, and locations close to where they live.

The rapid growth of outlets coupled with the location of outlets that are close to one another makes increasingly fierce competition between minimarkets. Besides, the profit earned by retailers from this business is not too high, which is around $7 \%$ to $15 \%$ of turnover. This is what requires retailers to apply rules to retail or strategies to make it known where they can target the right customers who might benefit their business[1]. Every day the minimarket accumulates transaction data in large numbers, if one day there are 100 transactions, in a year there are at least 36500 transactions, it can be imagined if it has been for years. Then this data is stored just like that until it is mountainous in number, stored on the grounds as an annual archive and seen only how much income and how much expenditure without trying to dig deeper into the meaning of the size of the data.Emergence of data mining is based on the fact that the amount of data stored in the database is getting bigger. Analysis of shopping basket data (Market basket analysis) which always experiences data input every day to look for relationships between goods based on rules called the association rule.
Association rule was first introduced by R.Agrawal which is used to look for interesting correlations/ relationships, looking for patterns that often arise and the structure of associations between itemset, because it originated from the study of customer transaction databases to determine the habits of a product purchased together[2]. Data mining using the association rules method can be used to find interesting relationships hidden in large data sets[3].

In supporting the search for associations or relationships between these items, the Equivalence CLASS Transformation (Eclat) algorithm is used because the fastest Eclat algorithm between Apriori and FPGworth is at the time of support and confidence execution. It was also identified that the execution time decreased with increasing support and confidence [4]. So that the analysis will get the best-selling item configuration, goods that can be crossselling or up-selling to regulate rather than the layout of the goods in the display window.

More than that, the purpose of the research is how to get the relationship between goods which are then bundled up to get more income than before and the right promotion. Besides, the initial stage of the test is to divide data from one transaction year into testing per three months (quarterly), from each quarter displayed the most sold goods and display visualizations every quarter.

\section{Related Research}

\section{Eclat}

Eclat is a data mining algorithm known as the first search depth search, transformation from horizontal to vertical 
data using intersect / TID intersection as a mining step. Eclat algorithm has also been used in various studies which of course are related to data mining.

Study of the factors that cause accidents and patterns of accidents that often occur. The mining rules of the association "Eclat Algorithm" are used to predict the relationship between various traffic accidents using a traffic dataset[5].

Help find deleted or web crawlers via retrieved keywords taken by the system. Using the efficient rules of the Eclat Algorithm, to determine the important words for mining frequent patterns, and the whole process is catalyzed by the classification of fuzzy logic for the process of linking patterns more easily[6].

School education assessment systems, to solve problems that are appropriate to the needs of the right students and the teaching requirements of teachers, can increase the level of teacher knowledge and the quality of school education. Using data mining association rules namely, Eclat to further deepen data evaluation, to facilitate realtime analysis and updating data, and to enhance the effect of work visibility improve student understanding. Through the rules of the association, teacherage, education, professional degree, age research, and advanced research on evaluation results[7].

Membrane computing is computing the structure and function of living cells. This study uses a system such as tissue with an active membrane to mine frequent patterns. The aim is to find out what attributes often appear together, to find frequent patterns in a database. Using the Eclat algorithm the difficulty of time decreases to $\mathrm{O}(\mathrm{t})$ from $\mathrm{O}$ (t2). Calculations only require a few cells, which can reduce computational resource requirements and increase computational efficiency[8].

Cognitive radio (CR) is an efficient and opportunistic use of the frequency spectrum to increase spectral efficiency. Use the eclat algorithm to find items that appear frequently itemsets. Then to find out which itemset often appear with a strong trust value, which is $100 \%$, to further determine. Try to support the relationship between the attackers who collude and try to support them. Evaluation results prove the support submitted is better than detection based on traditional requirements[9].

\section{Association Rule}

Association rules are rules related to data mining methods used to conduct data mining and the purpose of obtaining relationships or relationships between goods. Various methods can be used in the association method.

In the case of items not being closed with strict evidence using the Newcharm algorithm, an optimization for Charm to mine frequently closed items that is more memory efficient, when executing two algorithms with higher min_sup. In solid datasets, the execution time of the two algorithms is very close, but Newcharm is still slightly better. The Charm algorithm shows a deficiency in memory consumption because it needs to store all items tucked in memory to evaluate whether it needs to be closed or not[10].

The research explores the main influencing factors in infrared countermeasures and reveals the effect of a combination of influential factors, adopting the association mining rule theory. Meanwhile, the FPGrowth algorithm is introduced to explore the association rules using off-line data and reveal the main influence factors. By building a concise data structure called FP-tree and Frequent Extract [11].

Linkruleminer (LRM) algorithms have excellent performance for various types of data to create frequent itemset. The linkruleminer algorithm is used to analyze workflows to produce more frequent itemset. The efficiency of this algorithm can also help reduce execution time with parallel processing properties. This can be simulated using message passing interface (MPICH), a parallel process software[12].

Choose association rules based on linguistic level aggregation on the extracted association rules. The association rules are chosen by using the order of aggregation results in the level of linguistic satisfaction. The sequence of linguistic aggregation results from the extracted association rules is used to select the satisfied association rules. Used to experiment with new methods, where association rules are extracted from Apriori, Eclat, FP-Growth or LCM algorithms[13].

One of the most important approaches is IFPGrowth, which has been proposed to mine the association rules efficiently. The experimental results show that IFP growth requires a relatively small memory space during the mining process. Regarding execution time, outperformed FPGrowth one to 300 times under different minimum support[14].

In this 212 data mart, it has a unique meaning that transaction data is recorded in a vertical form which means it has a duplicate transaction id to match the goods sold. In terms of goods sold, this minimarket sells goods that have the approval of the MUI (Majlis Ulama Indonesia). Judging from its history that 212 was founded based on Islamic sharia principles where based on the demography that Palembang's Kuto place is one of the largest bases of the Islamic group in Palembang. Based on the statistics of Palembang city in 2014 (BPS) Adherents of Islam in Kuto Palembang as many as 170086 inhabitants, ranked second throughout the city of Palembang, which is predicted that many transactions will occur in the minimarket. Therefore, the authors conducted the study.

\section{Methodology}

In analyzing shopping carts or transaction data, the method chosen for use is the association rule of the classification rule, the association rule can predict not only certain classes but can also predict many attributes at one time and have a minimum accounting rate of 95\%[15]. In searching for strong associations between items, the Eclat algorithm is used as a proof of the association rules, of all the algorithms used, Charm, dEclat, and Eclat have proven to be the best and suitable for large databases using minimum memory[16]. The above output will be a set of association rules in the form E.q 1 :

IF \{item 1, item 2$\}$ THEN $\{$ item 3$\}$

This is that when items 1 and 2 (antecedents) are purchased, item 3 (consequence) is likely to be purchased with a certain probability. To find the association rules in a data set, the item set must meet a minimum support threshold, also known as minimum support (MinSupport )[17]. The basic methodology as a parameter of the strength of the relationship between items in associative rules. association 
analysis is divided into three, the higher the value of support, the more often the itemset occurs[18]:

Looking for a combination of items E.q 2 that most often occur together in a transaction. Finds all sets of items that appear frequently with support $>=$ the specified number of min_support.

$\operatorname{Support}(A)=\frac{\text { Number of Transactions Containing } A}{\text { Total transactions }}$

Support, Indicates how much the level of dominance of an itemset of the whole transaction, This determines whether an itemset is worth seeking confidence.

After a combination of frequently occurring items E.q 3 is identified, look for associations. This step is often called the Association Rule Mining. List of all Association Rules from the set of items that appear frequently. Calculate support and confidence for all rules. Trim rules that fail to meet both min_support and min_confidence. Choose strong association.

$\operatorname{conf}\{A \rightarrow B\}=\frac{f(A \cup B)}{f(A)}$

Confidence, A measure that shows the relationship between 2 items conditionally (for example, calculating the possibility of how often item $B$ is purchased by a customer if the customer purchases an item A).

Lift, The probability of items occurring together in a rule divided by left and right side multiplication support E.q 4, the higher the lift value, the stronger the connection between items[18].

$l=\operatorname{lift}\{A \rightarrow B\}=\frac{f(A \cup B)}{f(A) f(B)}$

Lift values illustrate the following:
If the value $<1$, then $\mathrm{A}$ and $\mathrm{B}$ have a low concurrent occurrence.

If the value $=1$, then $\mathrm{A}$ and $\mathrm{B}$ frequently occur in the data as expected.

If the value $>1$, then A and B occur simultaneously in the data more frequently as.

\section{Equivalence Class Transformation (Eclat)}

The fastest algorithm between Apriori and fpgworth at the time of support and confidence execution cause the algorithm uses a vertical base layout[15].. It was also identified that the execution time decreased with increasing support and confidence [4]. This algorithm uses intersections in the data to calculate candidate support, which is then tested to obtain itemset patterns. This involves the following steps [4]:

By changing data that is formatted horizontally to vertical format. The support count of the itemset is just the TID set length of the itemset.

Starting with $n=1$, $n$-itemset can often be used to construct candidates $(n+1)$-items based on Apriori properties. The calculation is done by cutting the TID set from the nitemset often to calculate the TID set from the corresponding set item $(n+1)$.

This process is repeated, with $n$ increasing by 1 each time until no set items are frequent or no set of candidate items can be found. In addition to taking advantage of Apriori properties in generating candidates $(n+1)$ - items from frequent n-itemset,

The several reasons for using the Eclat algorithm are Eclat algorithm is faster than Apriori or fp growth as shown Table 1.

Table 1. Execution Speed

\begin{tabular}{|l|l|l|l|l|}
\hline \multirow{2}{*}{ SUPPORT(\%) } & \multirow{2}{*}{ CONFIDENCE $(\%)$} & \multicolumn{3}{|l|}{ TOTAL EXECUTION IN SECOND } \\
\cline { 3 - 5 } & & APRIORI & FP GROWTH & ECLAT \\
\hline 1 & 5 & 0.115 & 179.23 & 0.065 \\
\hline 1 & 10 & 0.102 & 123.54 & 0.055 \\
\hline 2 & 5 & 0.1025 & 84.79 & 0.023 \\
\hline 2 & 10 & 0.06 & 25.58 & 0.0335 \\
\hline 5 & 13 & 0.018 & 8.46 & 0.0075 \\
\hline 6 & 15 & 0.028 & 6.58 & 0.007 \\
\hline 7 & 17 & 0.036 & 5.12 & 0.0037 \\
\hline
\end{tabular}


It is a depth-first search which saves more memory than breadth-first search. Based on memory consumption, the Eclat algorithm is more efficient Figure 1.

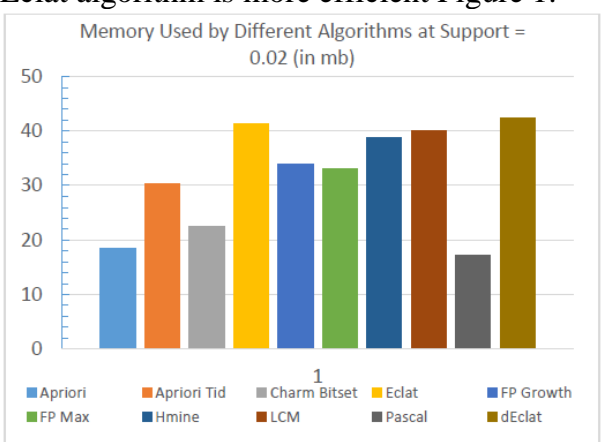

Figure 1. Efficiency Memory

Results and Discussion

Describe the results and analysis of research divided into 4 Quarters, namely identification of goods associations from (21 February 2018-21 May 2018), identification of goods associations from (22 May 2018-21 August 2018), identification of goods associations from (22 August 201821 November 2018). and the top 10 best-selling items per quarter. The amount of data tested 212 Mart Mart point of sales transaction data as of February 21 2018-21 February
2019 contains 58068 transactions with 140733 records and 47 attributes. in this test, the data between training and testing is defined. Split dataset into training (80\%) testing $(20 \%)$.

Quarter 1:

13261 [1: 13261] observer and 3036 variables. Training data of 10626 observers of 3036 variables. Data testing 2635 observers of 3036 variables

Quarter 2:

119781 [1: 11978] observer and 3172 variables. Training data of 9601 observers of 3172 variables. Testing data of 2377 observers of 3172 variables

Quarter 3:

12705 [1: 12705] observer and 3224 variables. Training data of 10141 observers of 3224 variables. Data testing 2564 observers of 3224 variables

Identification of associations between goods in the form of relationships between goods with parameters in the form of support, confidence and lift to the identification of the internal environment explores internal factors in the form of strengths and weaknesses, while the identification of top 10 best-selling items explores the items that sell the most in each quarter. the steps compiled to obtain a transaction association are Table 2.

Table 2. Scenario find Mining the Data

Step 1 Data aggregation, preprocessing and binarization of data in ETL

Step 2 ETL output is imported into Rstudio looking for minimum support to get the count of each item

Step 3 Data visualization of top 10 goods sold

Step 4 Lookin for associations by determining minimum support, minimum confidence and minimal relations (minlen)

Step 5 Visualization of the relationship between goods

Starting from cleansing, aggregation, preprocessing data in advance in ETL (Extract, Transform, Load) using Pentaho data integration 7.1. The data variables are of type double
( 1 and 0 ) so they can be expressed as a transactional matrix so that associations between goods can be identified. By starting the testing steps Table 3 as follows.

Table 3. Scenario Find Association
Step 1 Determine Minimum Support 2\% and minimum confidence 0.02
Step 2 Determine Minimum Support $0.5 \%$ and minimum confidence 0.05 and minimal relations 2
Step 3 Determine Minimum Support $0.1 \%$ and minimum confidence 1 and minimal relations 3
Step 4 Determine Minimum Support $0.03 \%$ and minimum confidence 1 and minimal relations 4 


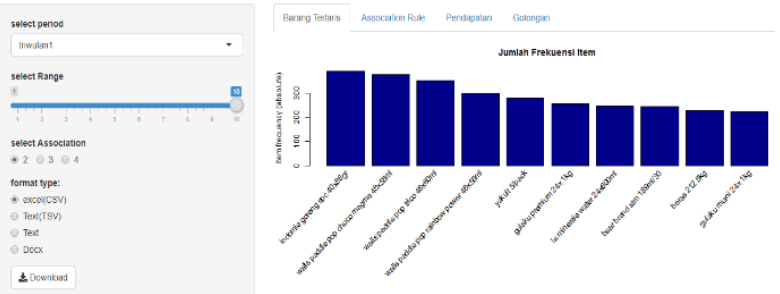

Figure 2. Diagram Top 10 goods Sold

From the search for top10 best-selling items Figure 2, utilizing rstudio tools, it is found that the best-selling item or the most purchased item is indomie goreng $86 \mathrm{gr}$ with quantity as 391 pieces. Next, the association search, starting from the minimum support (MINsupport) trial is equal to $2 \%$ and the minimum self-confidence level (MINconfidence) is set at 2. When the dataset has thousands of items and millions of transactions, the 0.02 threshold is considered reasonable or make fair sense is not too high and not too low. Then to get an interesting relationship, then the support threshold is redone back to 0.0003 with the level of confidence being increased to 1 or equal to $100 \%$ which means that item $\mathrm{y}$ is purchased if item $\mathrm{x}$ is purchased and the minimum association is increased to 4 as in Table 4.

MINsupport $=0.0003$ and MINconfidence $=1$ and $\operatorname{MINlen}($ minimum relation $)=4$

Table 4. Association Among 4 Itemsets

\begin{tabular}{|c|c|c|c|c|c|c|}
\hline Lhs & $\rightarrow$ & rhs & support & confidence & lift & count \\
\hline $\begin{array}{l}\text { \{frisian flag jelajah } 1-3 \text { cho } 800 \mathrm{~g} \text {, frisian flag } \\
\text { skm sch coklat } 40 \text { gr bd } 6 \text {, sun baby food beras } \\
\text { merah box } 120 \mathrm{gr}\}\end{array}$ & $\rightarrow$ & $\begin{array}{l}\text { \{cap enak sch plain } \\
\text { bd } 6 \times 20 \times 40 \mathrm{gr}\}\end{array}$ & 0.0003016364 & 1 & 368.3611 & 4 \\
\hline $\begin{array}{l}\text { \{frisian flag jelajah } 1-3 \text { cho } 800 \mathrm{~g} \text {, indomie } \\
\text { goreng spe } 40 \mathrm{x} 86 \mathrm{gr} \text {, sun baby food beras merah } \\
\text { box } 120 \mathrm{gr}\}\end{array}$ & $\rightarrow$ & $\begin{array}{l}\text { \{cap enak sch plain } \\
\text { bd } 6 \times 20 \times 40 \mathrm{gr}\}\end{array}$ & 0.0003016364 & 1 & 368.3611 & 4 \\
\hline $\begin{array}{l}\text { \{indomie goreng spc } 40 \mathrm{x} 86 \mathrm{gr} \text {, sun baby food } \\
\text { beras merah box } 120 \mathrm{gr} \text {, cap enak sch plain bd } \\
6 \times 20 \times 40 \mathrm{gr}\}\end{array}$ & $\rightarrow$ & $\begin{array}{l}\{\text { frisian flag jelajah } \\
1-3 \text { cho } 800 \mathrm{~g}\}\end{array}$ & 0.0003016364 & 1 & 884.0667 & 4 \\
\hline $\begin{array}{l}\text { \{frisian flag jelajah } 1-3 \text { cho } 800 \mathrm{~g} \text {, frisian flag } \\
\text { skm sch coklat } 40 \text { gr bd } 6 \text {, indomie goreng spc } \\
40 \times 86 \mathrm{gr}\}\end{array}$ & $\rightarrow$ & $\begin{array}{l}\text { \{cap enak sch plain } \\
\text { bd } 6 \times 20 \times 40 \mathrm{gr}\}\end{array}$ & 0.0003016364 & 1 & 368.3611 & 4 \\
\hline $\begin{array}{l}\{\text { kerupuk anggun } 250 \mathrm{gr} \text {, sweety silver pantz xl } \\
16 \times 18+2 \text {, cap enak sch plain bd } 6 \times 20 \times 40 \mathrm{gr}\}\end{array}$ & $\rightarrow$ & $\begin{array}{l}\text { \{indomie goreng } \\
\text { spc } 40 \times 86 \text { gr }\}\end{array}$ & 0.0003016364 & 1 & 33.9156 & 4 \\
\hline
\end{tabular}

Visualization of associations between goods in the first quarter is an association between goods used from the last combination, with a minimum of goods associations equal to 4 Figure 3.

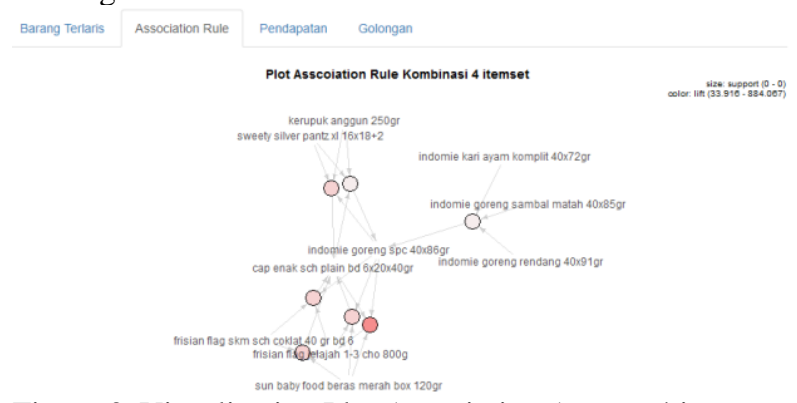

Figure 3. Visualization Plot Association Among 4 itemsets

Quarter 2 (May 22, 2018-21 August 2018) Has a binary matrix composition as follows:

11978 transactions (rows), 3172 items (columns)

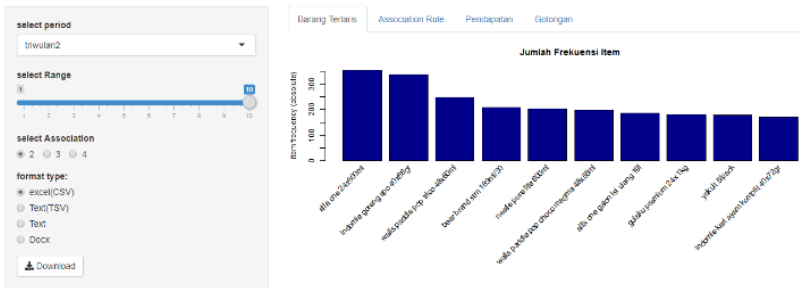

Figure 4. Diagram Top10 Goods Sold

From the search for top10 best-selling items Figure 4, utilizing rstudio tools, we get that the best-selling item or the most purchased item is the alpha one $600 \mathrm{ml}$ with the quantity as 355 pieces. Furthermore, the association search, starting from the minimum support (MINsupport) trial is equal to $2 \%$ and the minimum level of self-inquiry (MIN confidence) is set at 2\%. Then to get an interesting relationship, then the support threshold is reduced again to 0.0003 with the confidence level increased to 1 or equal to $100 \%$ and the minimum association is increased to 4 as in Table 5.

MINsupport $=0.0003$ and MINconfidence $=1$ and MINlen (minimum relation $)=4$ 
Table 5. Association among 4 Itemsets

\begin{tabular}{|c|c|c|c|c|c|c|}
\hline lhs & $\rightarrow$ & rhs & support & confidence & lift & count \\
\hline $\begin{array}{l}\text { \{gulaku murni } 24 \times 1 \mathrm{~kg} \text {, indomie kari ayam } \\
\text { komplit } 40 \times 72 \mathrm{gr} \text {, indomie rasa mi celor } \\
40 \times 75 \mathrm{gr}\}\end{array}$ & $\rightarrow$ & $\begin{array}{l}\text { \{indomie goreng spc } \\
40 \times 86 \mathrm{gr}\}\end{array}$ & 0.0004174320 & 1 & 35.64881 & 5 \\
\hline $\begin{array}{l}\text { \{cap enak sch plain bd } 6 \times 20 \times 40 \text { gr, frisian flag } \\
\text { skm sch coklat } 40 \text { gr bd } 6 \text {, sun baby food beras } \\
\text { merah box } 120 \text { gr }\}\end{array}$ & $\rightarrow$ & $\begin{array}{l}\text { \{indomie goreng spc } \\
40 \times 86 \mathrm{gr}\}\end{array}$ & 0.0003339456 & 1 & 35.64881 & 4 \\
\hline $\begin{array}{l}\text { \{frisian flag skm sch coklat } 40 \text { gr bd } 6, \\
\text { indomie goreng spc } 40 \times 86 g r \text {, sun baby food } \\
\text { beras merah box } 120 \mathrm{gr}\}\end{array}$ & $\rightarrow$ & $\begin{array}{l}\text { \{cap enak sch plain } \\
\text { bd } 6 \times 20 \times 40 \mathrm{gr}\}\end{array}$ & 0.0003339456 & 1 & 570.38095 & 4 \\
\hline $\begin{array}{l}\text { \{cap enak sch plain bd } 6 \times 20 \times 40 \mathrm{gr} \text {, indomie } \\
\text { goreng spc } 40 \mathrm{x} 86 \mathrm{gr} \text {, sun baby food beras } \\
\text { merah box } 120 \mathrm{gr}\end{array}$ & $\rightarrow$ & $\begin{array}{l}\text { frisian flag skm sch } \\
\text { coklat } 40 \text { gr bd } 6\}\end{array}$ & 0.0003339456 & 1 & 704.58824 & 4 \\
\hline
\end{tabular}

Visualization of associations between goods in the second quarter is an association between goods used from the last combination, with a minimum of goods associations equal to 4 Figure 5.

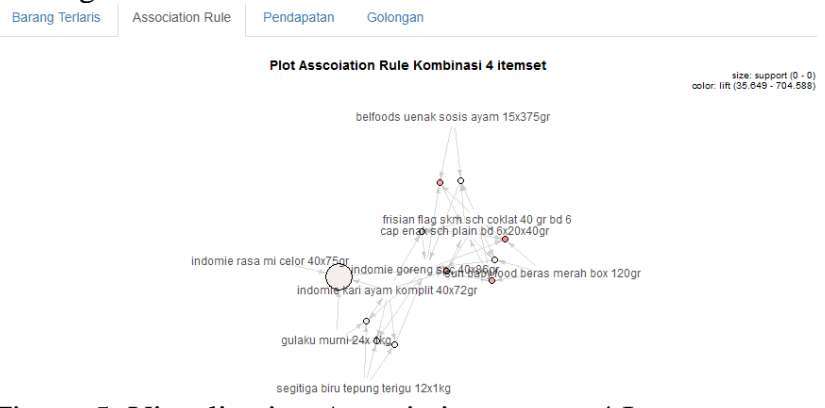

Figure 5. Visualization Association among 4 Itemsets Quarter 3 (August 22, 2018-21 November 2018) Has a binary matrix composition as follows:

12705 transactions (rows), 3224 items (columns)

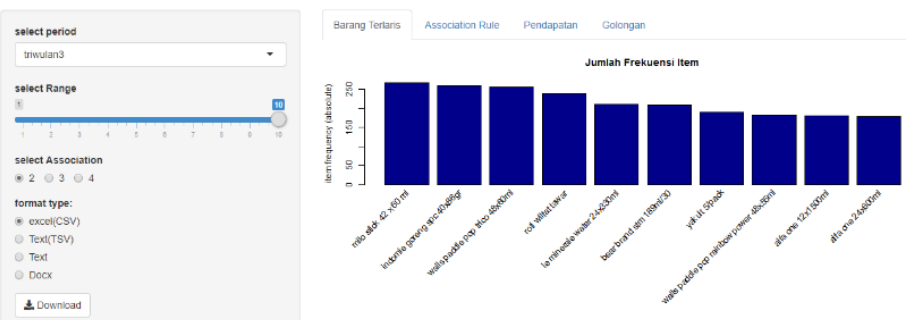

Figure 6. Diagram Top10 Goods Sold

From the search for top 10 bestsellers Figure 6, utilizing rstudio tools, we get that the best-selling item or the most purchased item is $60 \mathrm{ml}$ milo stick with quantity as 268 pieces. Furthermore, the search for associations, starting from the minimum support (MINsupport) trial is equal to $2 \%$ and the minimum level of self-inquiry (MIN confidence) is set at $2 \%$. Then to get an interesting relationship, then the support threshold is reduced again to 0.0003 with the confidence level increased to 1 or equal to $100 \%$ and the minimum association is increased to 4 as in Table 6.

MINsupport $=0.0003$ and MINconfidence $=1$ and $\operatorname{MINlen}($ minimum relation $)=4$

Table 6. Association among 4 Itemsets

\begin{tabular}{|c|c|c|c|c|c|c|}
\hline lhs & $\rightarrow$ & rhs & support & confidence & lift & count \\
\hline $\begin{array}{l}\text { \{indomie goreng kriuk pedas } 40 \times 90 \mathrm{gr} \text {, } \\
\text { indomie goreng spc } 40 \times 86 \mathrm{gr} \text {, indomie kari } \\
\text { ayam komplit } 40 \times 72 \mathrm{gr}\}\end{array}$ & $\rightarrow$ & $\begin{array}{l}\text { \{indomie goreng } \\
\text { kriuk pedas } \\
\left.40 \times 90 \mathrm{gr} \_1\right\}\end{array}$ & 0.0008658009 & 1 & 147.73256 & 11 \\
\hline $\begin{array}{l}\text { \{indomie goreng spc 40x86gr, indomie kari } \\
\text { ayam komplit } 40 x 72 \mathrm{gr} \text {, indomie goreng kriuk } \\
\left.\text { pedas } 40 x 90 \mathrm{gr} \_1\right\}\end{array}$ & $\rightarrow$ & $\begin{array}{l}\text { \{indomie goreng } \\
\text { kriuk pedas } 40 \mathrm{x} 90 \mathrm{gr} \text { \} }\end{array}$ & 0.0008658009 & 1 & 147.73256 & 11 \\
\hline $\begin{array}{l}\text { \{indomie goreng kriuk pedas } 40 \times 90 \mathrm{gr}, \\
\text { indomie goreng spc } 40 \mathrm{x} 86 \mathrm{gr} \text {, indomie rasa mi } \\
\text { celor } 40 \times 75 \mathrm{gr}\}\end{array}$ & $\rightarrow$ & $\begin{array}{l}\text { \{indomie goreng } \\
\text { kriuk pedas } \\
\left.40 x 90 g r \_1\right\}\end{array}$ & 0.0006296734 & 1 & 147.73256 & 8 \\
\hline $\begin{array}{l}\text { \{indomie goreng spc } 40 \times 86 \mathrm{gr} \text {, indomie } \\
\text { goreng kriuk pedas } 40 \times 90 \mathrm{gr} \text { _1, indomie rasa } \\
\text { mi celor } 40 \times 75 \mathrm{gr}\}\end{array}$ & $\rightarrow$ & $\begin{array}{l}\{\text { indomie goreng } \\
\text { kriuk pedas } 40 \times 90 \mathrm{gr}\}\end{array}$ & 0.0006296734 & 1 & 147.73256 & 8 \\
\hline
\end{tabular}


Visualization of associations between goods in quarter 3 is an association between goods used from the last combination that is with a minimum of goods associations equal to 4 Figure 7.

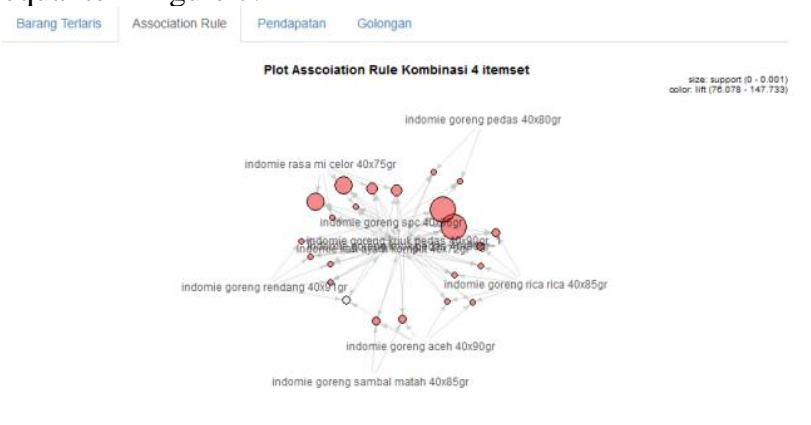

Figure 7. Visualization Association among 4 Itemsets Analysis of the test results is done by doing calculations using the confusion matrix model. The following is the result of confusion matrix calculation as in Table 7.

Table 7. confusion matrix

\begin{tabular}{|l|l|l|l|}
\hline \multicolumn{2}{|c|}{} & \multicolumn{2}{c|}{ Actual } \\
\cline { 3 - 4 } \multicolumn{2}{|c|}{} & True & False \\
\hline \multirow{2}{*}{ Prediction } & True & 13926 & 1176 \\
\cline { 2 - 4 } & False & 1755 & 16707 \\
\hline
\end{tabular}

Precision

$\begin{array}{ll}=92 \% & \mathrm{TP} /(\mathrm{TP}+\mathrm{FP})=13926 /(13926+1176)=0.92 * 100 \% \\ \text { Recall } & \mathrm{TP} /(\mathrm{TP}+\mathrm{FN})=13926 /(13926+1755)=0.88 * 100 \%\end{array}$

$=88 \%$

Accuracy

$(\mathrm{TP}+\mathrm{TN}) /(\mathrm{TP}+\mathrm{TN}+\mathrm{FP}+\mathrm{FN})=(13926+16707) /(13$ $926+1176+1755+16707)=0.912=91.2 \%$

Based on testing and analysis of the results of tests carried out, with an accuracy rate of $91.2 \%, 92 \%$ precision, and $88 \%$ recall showing a value of almost one hundred percent accurate, accurate precision and recall that are still in good category, support in implementing research and representing predictions and actual (actual) conditions of the data.

\section{CONCLUSION}

Minimarket 212 Palembang Kuto Market experienced the sale and purchase of goods transactions totaling 51,068 transactions during the period February 21 2018-21 February 2019. During that period 140,733 items were sold with details of 4,522 kinds of items sold with nonfood 2037 $(45 \%)$ types of items, food group 1327 (29\%) kinds of items, drink class $795(18 \%)$ kinds of items, consignment group $329(7 \%)$ kinds of items and frozen group $34(1 \%)$ kinds of items. 256 kinds of items were only sold 1 time in the period and the remaining 4,266 items were sold more than one. The most sold item during this period was indomie goreng spc 86gr totaling 1321 (29\%) pieces. Money collected during the period amounted to Rp2,776,995,081 and refunds amounted to Rp271,271,881. The relationship between goods obtained is in the first quarter If you buy crackers, diapers. Milk sachets then buy instant noodles. In quarter 2 If you buy noodles, flour then buy sugar. In quarter 3 If you buy instant noodles, buy other instant noodles

\section{ACKNOWLEDGMENT}

This research was financially supported by the Sriwijaya University. Thank Lecture who have contributed towards development of the idea

\section{REFERENCES}

[1] G. L. Prajapati, D. Ahilya, D. Ahilya, and D. Ahilya, "The Role of Apriori Algorithm for Finding the Association Rules in Data Mining," Int. Conf. Issues Challenges Intell. Comput. Tech., pp. 657-660, 2014.

[2] M. Sethi, "Sandwich-Apriori : A Combine Approach of Apriori and Reverse-Apriori," in IEEE INDICON, 2018, no. December 2015.

[3] M. Kaur and S. Kang, "Market Basket Analysis : Identify the changing trends of market data using association rule mining," Procedia-Procedia Comput. Sci., vol. 85, no. Cms, pp. 78-85, 2016.

[4] G. Sinha and S. M. Ghosh, "Identification of Best Algorithm in Association Rule Mining Based on 
Performance," Int. J. Comput. Sci. Mob. Comput., vol. 3, no. 11, pp. 38-45, 2014.

[5] K. R. Sumana, Deekshitha, and Phaneendra, "Smart Automated Modelling using Eclat Algorithm for Traffic Accident Smart Automated Modelling using Eclat Algorithm for Traffic Accident Prediction," Int. Res. J. Eng. Technol., vol. 06, no. 05, pp. 6682-6685, 2019.

[6] P. P. Doshi, "Web Pattern Mining using ECLAT," Int. J. Comput. Appl., vol. 179, no. 8, pp. 9-14, 2017.

[7] Y. Dou, X. Fei, R. Zhu, T. Gao, Y. Wu, and L. Ma, "Application of Improved Eclat Algorithm in Students ' Evaluation of Teaching," MATEC Web Conf., vol. 01017, pp. 1-5, 2018.

[8] L. Jia, L. Xiang, and X. Liu, “An Improved Eclat Algorithm Based on Tissue-Like P System with Active Membranes," Processes, vol. 555, no. 7, pp. 1-15, 2019.

[9] F. Jin, V. Varadharajan, and U. Tupakula, “An Eclat Algorithm Based Energy Detection for Cognitive Radio Networks," IEEE Comput. Soc., pp. 1096-1102, 2017.

[10] X. Ye, F. Wei, F. Jiang, and S. Cheng, “An Optimization to CHARM Algorithm for Mining Frequent Closed Itemsets," IEEE Int. Conf. Comput. Inf. Technol., pp. 226-235, 2015.

[11] X. Yang, F. Yang-wang, W. You-li, Z. Dan-xu, and H. Chen, "Association Rule Mining for the Infrared Countermeasure by the PF-Growth Algorithm," in 2018 37th Chinese Control Conference (CCC), 2018, pp. 8043-8048.
[12] M. S. Saravanan and G. T. Bellarmine, "Analysis of Frequent Patterns in Dyeing Processing System using Association Rule Mining algorithms," IEEE, pp. $1-6,2012$.

[13] F. Ren, Z. Pei, and K. Wu, "Selection of Satisfied Association Rules via Aggregation of Linguistic Satisfied," IEEE Access, vol. 4, pp. 1-17, 2019.

[14] K. Lin, I. Liao, and Z. Chen, "Expert Systems with Applications An improved frequent pattern growth method for mining association rules," Expert Syst. Appl., vol. 38, no. 5, pp. 5154-5161, 2011.

[15] Kholod and Marina, "Market basket analysis of convenience store POS data," Annu. Rep. Econ. Soc. Univ., vol. 71, no. 3, pp. 183-204, 2010.

[16] B. Nigam, A. Nigam, and P. Dalal, "Comparative Study of Top 10 Algorithms for Association Rule Mining," Int. J. Comput. Sci. Eng., vol. 5, no. 8, pp. 190-195, 2017.

[17] J. Jiao and Y. Wang, "A new Tag Recombinant Approach Based on Apriori Algorithm," 2018 IEEE Int. Conf. Inf. Commun. Signal Process., no. Icsp, pp. 90-93, 2018.

[18] K. Tatiana, M. Mikhail, K. Tatiana, and M. Mikhail, "Market basket analysis of heterogeneous data sources for recommendation system improvement," Procedia Comput. Sci., vol. 136, pp. 246-254, 2018 